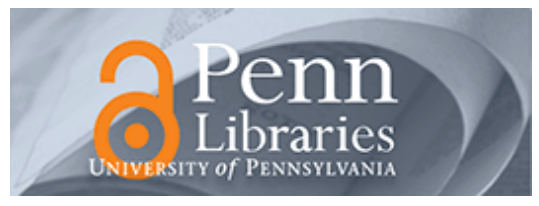

University of Pennsylvania

ScholarlyCommons

Finance Papers

Wharton Faculty Research

2007

\title{
The Reaction of Consumer Spending and Debt to Tax \\ Rebates-Evidence From Consumer Credit Data
}

Sumit Agarwal

Chunlin Liu

Nicholas S. Souleles

University of Pennsylvania

Follow this and additional works at: https://repository.upenn.edu/fnce_papers

Part of the Finance Commons, and the Finance and Financial Management Commons

\section{Recommended Citation}

Agarwal, S., Liu, C., \& Souleles, N. S. (2007). The Reaction of Consumer Spending and Debt to Tax Rebates-Evidence From Consumer Credit Data. Journal of Political Economy, 115 (6), 986-1019. http://dx.doi.org/10.1086/528721

This paper is posted at ScholarlyCommons. https://repository.upenn.edu/fnce_papers/250

For more information, please contact repository@pobox.upenn.edu. 


\title{
The Reaction of Consumer Spending and Debt to Tax Rebates-Evidence From Consumer Credit Data
}

\author{
Abstract \\ We use a new panel data set of credit card accounts to analyze how consumers responded to the 2001 \\ federal income tax rebates. We estimate the monthly response of credit card payments, spending, and \\ debt, exploiting the unique, randomized timing of the rebate disbursement. We find that, on average, \\ consumers initially saved some of the rebate, by increasing their credit card payments and thereby paying \\ down debt. But soon afterward their spending increased, counter to the permanent income model. \\ Spending rose most for consumers who were initially most likely to be liquidity constrained, whereas debt \\ declined most (so saving rose most) for unconstrained consumers.

\section{Disciplines} \\ Finance | Finance and Financial Management
}




\title{
The Reaction of Consumer Spending and Debt to Tax Rebates-Evidence from Consumer Credit Data
}

\section{Sumit Agarwal}

Federal Reserve Bank of Chicago

\section{Chunlin Liu}

University of Nevada, Reno

\section{Nicholas S. Souleles}

University of Pennsylvania and National Bureau of Economic Research

\begin{abstract}
We use a new panel data set of credit card accounts to analyze how consumers responded to the 2001 federal income tax rebates. We estimate the monthly response of credit card payments, spending, and debt, exploiting the unique, randomized timing of the rebate disbursement. We find that, on average, consumers initially saved some of the rebate, by increasing their credit card payments and thereby paying down debt. But soon afterward their spending increased,
\end{abstract}

We would like to thank the editor and two referees, Bob Hunt, Alan Krueger, Joanne Maselli, Larry Mielnicki, Jim Papadonis, Jonathan Parker, Anthony Santomero, Joel Slemrod, Melvin Stephens, and seminar participants at the European Central Bank, Princeton University, the Allied Social Science Associations meetings, Harvard University, the Federal Reserve Banks of New York and Chicago, the Federal Reserve Board of Governors, Singapore Management University, National Singapore University, the University of Wisconsin-Milwaukee, the University of Nevada-Reno, the 2003 NBER Summer Institute, the Federal Reserve Bank of Philadelphia, and the University of Pennsylvania, as well as the Wharton Financial Institutions Center and the Rodney L. White Center for Financial Research. We are grateful to Diana Andrade and Ron Kwolek for their excellent research assistance. The views expressed are those of the authors alone and do not necessarily represent those of the Federal Reserve Bank of Chicago.

[Journal of Political Economy, 2007, vol. 115, no. 6]

(C) 2007 by The University of Chicago. All rights reserved. 0022-3808/2007/11506-0003 $\$ 10.00$ 
counter to the permanent income model. Spending rose most for consumers who were initially most likely to be liquidity constrained, whereas debt declined most (so saving rose most) for unconstrained consumers.

\section{Introduction}

This article uses a unique, new panel data set of thousands of credit card accounts to analyze how consumers respond to "lumpy" increases in income such as tax rebates. Specifically, to what extent did consumers use the 2001 federal income tax rebates to increase spending or to pay down debt? About two-thirds of U.S. tax filers received the rebates, typically $\$ 600$ for couples and $\$ 300$ for singles, for an average gain of about $\$ 500$ per recipient household. ${ }^{1}$ This represents a historically significant tax cut, corresponding to about 5 percent of quarterly median family income. In aggregate about $\$ 38$ billion of rebates were disbursed, which corresponds to about 2 percent of quarterly personal consumption expenditures. ${ }^{2}$ Our analysis will exploit a key feature of the rebate disbursement-its randomized timing. The rebate checks were disbursed over 10 successive weeks from July through September 2001, depending on the second-to-last digit of the recipients' social security numbers. ${ }^{3}$ Because this penultimate digit is randomly assigned, the timing of rebate receipt represents truly exogenous variation. Such randomization is quite rare in the history of fiscal policy and provides a unique natural experiment that cleanly identifies the causal effects of the rebates.

Although our estimation does not depend on any particular economic model, the results can be interpreted as a novel test of the canonical life cycle/permanent income (LCPI) model. In particular, in our highfrequency framework the rebates can be thought of as being prean-

\footnotetext{
${ }^{1}$ The rebates were used to deliver the benefits of reducing the lowest federal income tax bracket (which applied to the first $\$ 12,000$ of taxable income for joint returns, the first $\$ 6,000$ for individual returns, and the first $\$ 10,000$ for heads of households) from 15 percent to 10 percent. According to unpublished estimates from the Treasury, about 89.5 million tax returns received a rebate and 23.5 million did not receive a rebate, and about 22.9 million households did not file and so also did not receive rebates (Office of Tax Analysis). The average gain at the household level was calculated by Johnson, Parker, and Souleles (2006) using the Consumer Expenditure Survey.

${ }^{2}$ These calculations draw on Shapiro and Slemrod (2003a). The rebates represented the dominant component (about 84 percent) of the tax cuts implemented in the first year of the Economic Growth and Tax Relief Reconciliation Act of 2001. The timing of the remaining, smaller components in 2001 is independent of the randomized timing of the rebates analyzed here. For more details about the act, see Auerbach (2002), Kiefer et al. (2002), and Shapiro and Slemrod (2003a, 2003b).

${ }^{3}$ Taxpayers who had filed their year 2000 returns late could receive the rebate later than this, but typically about 92 percent of filers file on time (Slemrod et al. 1997). Our analysis does not use any variation resulting from late returns.
} 
nounced: Congress passed the Economic Growth and Tax Relief Reconciliation Act in May 2001, and expectations of some tax cut arose even earlier. ${ }^{4}$ Hence under the LCPI model, consumption should not significantly increase at the time of rebate receipt. Most previous tests of the model in micro data have had trouble identifying such predictable changes in income, which might have biased some of the tests against rejecting the model (Shea 1995). Further, even studies that reject the model often find it difficult to identify the source of their rejection. The leading alternative model allows for liquidity constraints, but there is still no consensus about their actual importance. (For a useful review of the literature see Browning and Lusardi [1996].) Part of this disagreement is due to difficulties identifying which households in the data are in fact constrained. Most studies split the sample on the basis of net worth, but net worth conflates credit demand and credit supply. The fact that someone has low (even negative) net worth does not necessarily imply that he has reached his borrowing limit (Jappelli 1990). One advantage of using credit card data is that they separately record credit limits and credit balances, which helps distinguish credit supply and demand (Gross and Souleles 2002).

Using innovative questions about the 2001 rebate that were added to the Michigan Survey of Consumers, Shapiro and Slemrod (2003a) found that about 46 percent of respondents who received (or expected to receive) a rebate reported that it would mostly lead them to pay down debt (and another 32 percent of respondents reported that they would mostly save the rebate, in the sense of accumulating assets). This finding further justifies our focus on credit cards, whose debt carries higher interest rates than other forms of consumer debt. Rebate recipients who pay down debt should generally first pay down any credit card debt they hold. We use distributed lag models that are interpretable as event studies to estimate the month-by-month response of credit card payments, spending, and debt to the tax rebates. This allows us to determine whether there are salient dynamics in consumers' response to the rebates and, if so, helps identify the mechanisms behind the dynamics. For instance, if consumers initially use the rebates to pay down debt (or otherwise save) and thereby improve their balance sheets, what does this imply about their subsequent spending?

Because credit cards play an important role in consumer finances, they can be quite useful for studying consumer behavior. About 20 percent of aggregate personal consumption is being purchased using credit cards (Chimerine 1997). Moreover, for most households, credit

\footnotetext{
${ }^{4}$ Indeed, tax cuts were a central element of George W. Bush's platform in the 2000 election. Moreover, the Treasury sent taxpayers a letter in advance informing them of the size of their upcoming rebate and the particular week in which it would be disbursed.
} 
cards, in particular bank cards (e.g., Visa, MasterCard, Discover, and Optima cards), represent the leading source of unsecured credit. ${ }^{5}$ About two-thirds of households have at least one bank card, and of these households at least 56 percent are borrowing on their bank cards, that is, paying interest, not just transacting (1995 Survey of Consumer Finances $[\mathrm{SCF}]) .{ }^{6}$ Conditional on borrowing, in the mid to late 1990s the typical bank card account was borrowing about $\$ 2,000$, with the account holder having roughly another $\$ 5,000$ of balances on other cards. These are large magnitudes relative to typical household balance sheets. They are also large in the aggregate: Total credit card balances currently amount to about $\$ 900$ billion (Federal Reserve Board of Governors 2007).

Previewing the results, we find that, on average, consumers initially saved some of the rebate, by increasing their credit card payments and thereby paying down debt and increasing their liquidity. But soon afterward their spending increased, counter to the LCPI model and Ricardian equivalence. For consumers whose most intensively used credit card account is in the sample, spending on that account rose by over $\$ 200$ cumulatively over the nine months after rebate receipt, which represents over 40 percent of the average household rebate. We also find other significant heterogeneity across different types of consumers. Notably, spending rose most for consumers who, according to various criteria, were initially most likely to be liquidity constrained. By contrast, debt declined most (so saving rose most) for unconstrained consumers. These results suggest that liquidity constraints are important. More generally, the results suggest that there can be important dynamics in consumers' response to "lumpy" increases in income such as tax rebates, working in part through balance sheet (liquidity) mechanisms.

Sections II and III discuss the data and the econometric methodology. The main results appear in Section IV. Section V discusses related literature and Section VI presents conclusions. Appendices A, B, and C contain some additional results and data description.

\section{Data}

We use a unique, proprietary data set from a large financial institution that issues credit cards nationally. The data set contains a representative

\footnotetext{
${ }^{5}$ Moreover, Jappelli, Pischke, and Souleles (1998) found that households with bank cards are better able to smooth their consumption past income fluctuations than households without bank cards.

${ }^{6}$ As discussed by Gross and Souleles (2002), this figure probably understates the actual fraction of households borrowing on their bank cards, because SCF households appear to underreport their bank card debt. This paragraph draws heavily on the article by Gross and Souleles. See also Yoo (1998).
} 
sample of about 75,000 credit card accounts open as of June 2000, followed monthly for 24 months. ${ }^{7}$ The bulk of the data consists of the main billing information listed on each account's monthly statement, including total monthly payments, spending, balances, and debt, as well as the credit limit. Note that credit cards can be used for both transactions and borrowing purposes. "Debt" includes only interest-incurring balances that are rolled over, whereas "balances" also includes transactions balances that are paid off.

The data set also contains some credit bureau data about the other credit cards held by each account holder, in particular the number of other cards and their combined balances. (The credit bureaus do not separately record credit card debt, spending, or payments; they record only balances.) The credit card issuer obtained these data from the credit bureaus quarterly. Finally, there is some limited demographic data, that is, the age and marital status of the account holders. (Account holders are assumed to be married if there is a spouse also listed on the account.) An important advantage of the underlying data source is that it also included a variable indicating the penultimate digit of the account holders' social security numbers. This variable was used to identify the time of rebate receipt.

This data set has a number of additional advantages. Relative to traditional household data sets such as the SCF, the sample is large with little measurement error. Also, because each account is observed over many months, it is possible to study high-frequency dynamics. However, using credit card data does entail a number of limitations. The main unit of analysis is a credit card account, not an individual (who can hold multiple accounts). We partially circumvent this limitation by using the available data about the account holders from the credit bureaus. Also, we do not observe household assets or total spending (i.e., spending via cash and checks). ${ }^{8}$ Table 1 provides summary statistics for the main

\footnotetext{
${ }^{7}$ The sample excludes bankrupt/delinquent and dormant/closed accounts, which is consistent with our interest in accounts that might potentially respond to the rebates.

${ }^{8}$ As discussed below, as a result of such limitations, our main results are likely to understate the full effect of the rebates per account holder and per household. Nonetheless, our results are broadly consistent with the consumption dynamics (described below, also over a nine-month horizon) found by Johnson et al. (2006) using the Consumer Expenditure Survey, which records total household spending but does not separately distinguish spending via credit cards, cash, or checks. Also, credit card data could capture a different fraction of the response of total household debt (and total debt payments) relative to the response of total spending. For example, if rebate recipients who pay down debt disproportionately pay down their high-interest credit card debt but do relatively more of their increased spending via checks and cash, then the credit card data could capture more of the total response of debt than of spending. However, the article by Johnson et al. finds that the largest consumption response to the rebate came in apparel, which is relatively likely to be purchased using credit cards.
} 
TABLE 1

Sample Statistics $(N=739,945)$

\begin{tabular}{lcc}
\hline \hline Variable & Mean $(\$)$ & $\begin{array}{c}\text { Standard } \\
\text { Deviation }(\$)\end{array}$ \\
\hline Payments & 349 & 939 \\
Spending & 327 & 895 \\
Debt & 1,788 & 2,866 \\
Balances & 2,144 & 2,958 \\
Other balances & 7,871 & 13,030 \\
Credit limit & 8,584 & 3,353 \\
$\Delta$ payments & -5.3 & $1,234.7$ \\
$\Delta$ spending & -1.5 & $1,098.7$ \\
$\Delta$ debt & 1.2 & $1,045.3$ \\
\hline
\end{tabular}

NotE. - The data come from the monthly billing statement of credit card accounts, except for "other balances" on the other credit cards held by the account holders, which are obtained quarterly from the credit bureaus. All values are averaged over the sample period (March 2001-May 2002) used in the baseline results in table 2 and are quoted in current dollars. The differences $(\Delta)$ measure average monthly changes over the sample period.

variables used below. Appendix $\mathrm{C}$ provides further details about the data.

\section{Methodology}

We analyze the response of credit card account holders to the tax rebates, beginning with the monthly account-level data and later turning to the credit bureau data. Specifically, we estimate distributed lag models of the following form:

$$
Y_{i, t}=\alpha^{\prime} \text { time }_{t}+\beta_{0} R_{i, t}+\beta_{1} R_{i, t-1}+\beta_{2} R_{i, t-2}+\cdots+\beta_{9} R_{i, t-9}+\varepsilon_{i, t},
$$

where $R_{i, t}$ is an indicator variable for whether the holder of account $i$ received a rebate in month $t$. The dependent variable $Y_{i, t}$ variously represents either the spending $\left(S_{i, t}\right)$ or payments $\left(P_{i, t}\right)$ in account $i$ in month $t$, or the amount of debt held by account $i$ at the end of month $t\left(D_{i, t}\right)$. Because rebate receipt is a temporary event and debt is a stock variable, to allow for potentially persistent effects of the rebate on debt, the specification for debt uses the change in debt as the dependent variable $\left(Y_{i, t}=\Delta D_{i, t} \equiv D_{i, t}-D_{i, t-1}\right)$. Since payments and spending are flow variables linked to the change in debt via an accounting identity, payments and spending are accordingly analyzed in levels $\left(Y_{i, t}=S_{i, t}\right.$ or $\left.P_{i, t}\right)$. The vector time represents a complete set of month indicator variables, that is, a separate indicator for each month in $t=$ March 2001-May 2002, which is the available sample period given the original data set and the lags utilized in estimation. These indicator variables control for all aggregate effects, such as seasonality, the recession, changes in monetary policy, and so forth. 
As in Gross and Souleles (2002), the results can be interpreted as an event study. The coefficient $\beta_{0}$ measures the immediate response of the dependent variable to rebate receipt, in dollar terms. The marginal coefficients $\beta_{1}, \beta_{2}, \ldots$, and $\beta_{9}$ measure the additional responses one month after rebate receipt, two months later, ..., and nine months later, respectively. (Allowing for nine lags is consistent with the available data period and turned out in the baseline analysis to be sufficient for the results to converge.) Therefore, for debt the cumulative coefficients $b_{s} \equiv \sum_{t=0}^{s} \beta_{t}$ give the total change in debt after $s$ months, $s=0-9$. For the flow variables payments and spending, $b_{s}$ gives the cumulative sum of changes in payments or spending over the first $s$ months. For instance, if spending rises by $\beta_{0}=\$ 10$ in the month of rebate receipt and after one month spending is still $\beta_{1}=\$ 5$ greater than it was before receipt, then the cumulative effect on spending after month 1 is $b_{1}=\$ 15$.

To gauge the expansionary impact of the rebate, the response of spending is of central interest, especially the long-run cumulative response $b_{9}$. The responses of payments and debt are of independent interest and can also help shed light on the response of spending. Under our specification the responses of all three variables are naturally related: The total effect of the rebate on debt after $s$ months $\left(b_{s}^{\Delta D}\right)$ will approximately equal the difference of the cumulative effects of spending and of payments over the $s$ months $\left(b_{s}^{S}-b_{s}^{P}\right)$.

The key explanatory variable $R$ depends only on the penultimate digit of the account holders' social security numbers. Following the Treasury's disbursement timetable, we assume that rebates were disbursed in July 2001 to account holders with a penultimate digit of 0 or 1, in August 2001 to those with a digit of 2-6, and in September 2001 to those with a digit of 7-9. Since the digit is randomly assigned, the resulting variation in the timing of rebate receipt is exogenous by construction. In an extension we also briefly consider the response to rebates of different sizes, using the data on marital status. However, this variation is related to family structure and tax status (e.g., since couples filing jointly generally received the largest rebates) and so cannot be guaranteed to be exogenous. By contrast, $R$ uses only the part of the potential variation that is guaranteed to be exogenous and so allows for a clean test of whether there is a causal effect of the rebate on credit card usage. ${ }^{9}$

\footnotetext{
${ }^{9}$ In previous studies of the response of consumption to changes in income, the income change at issue was usually systematically related to various household characteristics, and so the estimated effect of the income change might spuriously reflect these characteristics. For instance, suppose that high-income households, which are more likely to own stocks, receive larger windfalls (or other income gains), and also that for other reasons the stock market happens to rise at the time of the windfall, leading high-income households to increase their consumption. In this case the estimated (unconditional) effect of the windfall on consumption would be exaggerated by the stock market appreciation. Here, by contrast, since the timing of rebate receipt is independent of other personal characteristics,
} 
Indeed, since the account holder in the data is not necessarily the member of the household who actually filed the tax return (and so whose social security number determined the timing of rebate receipt) and some households (effectively those with minimal tax liability) did not even receive a rebate, the results will likely understate the full effect of the rebate. ${ }^{10}$ Hence, by using the limited variation in $R$, we are setting a high hurdle for finding significant effects of the rebate.

As an extension, we will also examine the response of the balances on the other credit cards held by the account holders, using the credit bureau data. These data were collected only quarterly, however, which constrains their analysis. In interpreting these results we will accordingly focus on whether the response of other balances appears to reinforce, or to offset, the response of balances on the accounts in the main sample.

Unless indicated otherwise, equation (1) is estimated by ordinary least squares, with the standard errors adjusted for heteroscedasticity across accounts as well as serial correlation within accounts. We will also consider several alternative specifications. In particular, we will test whether the response to the rebate differs across different groups of account holders, such as those who are potentially liquidity constrained. Indicator variables for these groups will be added to equation (1), both directly and interacted with $R_{i, t}$ and all nine of its lags.

\section{Results}

We begin by estimating the average response of payments, spending, and debt to the rebate, using the credit card accounts in the main sample. We subsequently analyze the heterogeneity in response across different types of account holders. Because we find significant differences across account holders, we discuss these results in detail. Finally, we also examine the response of the other credit cards held by the account holders, using the credit bureau data.

Table 2 and figure 1 show the baseline results from applying equation (1) to payments, spending, and the change in debt in the main sample. The table reports the marginal coefficients $\beta_{s}, s=0-9$, along with the final cumulative coefficients $b_{9}$, which summarize the long-run effects of the rebate. The three graphs in figure 1 show the entire paths of cumulative coefficients $b_{s}, s=0-9$, along with their corresponding 95 percent confidence intervals. The results can be interpreted as an event

by comparing consumers who received rebates at different times, we avoid omitted variables bias and other confounding factors.

${ }^{10}$ Nonetheless, the person who opened the bank card account is probably most likely to be in charge of household finances and so disproportionately likely to be the tax filer. Recall that about a third of households did not receive rebates. However, consumers with credit cards are more likely to have received a rebate than those without credit cards. 
TABLE 2

Consumer Response to Rebates $(N=739,945)$

\begin{tabular}{|c|c|c|c|c|c|c|}
\hline & \multicolumn{2}{|c|}{ PAYMENTS } & \multicolumn{2}{|c|}{ SPENDING } & \multicolumn{2}{|c|}{$\Delta$ DEBT } \\
\hline & Coefficient & $\begin{array}{l}\text { Standard } \\
\text { Error }\end{array}$ & Coefficient & $\begin{array}{l}\text { Standard } \\
\text { Error }\end{array}$ & Coefficient & $\begin{array}{c}\text { Standard } \\
\text { Error }\end{array}$ \\
\hline$\overline{\beta_{0}}$ & 11.6 & $6.2^{*}$ & -2.8 & 5.6 & -14.3 & $7.2 * *$ \\
\hline$\beta_{1}$ & 11.4 & 8.1 & 6.2 & 7.2 & -6.0 & 9.0 \\
\hline$\beta_{2}$ & 8.2 & 9.2 & 2.7 & 8.5 & -7.2 & 10.1 \\
\hline$\beta_{3}$ & 3.8 & 10.1 & 7.6 & 9.3 & 5.0 & 10.9 \\
\hline$\beta_{4}$ & 8.9 & 10.9 & 8.3 & 10.0 & .3 & 11.7 \\
\hline$\beta_{5}$ & -1.9 & 11.4 & 8.3 & 10.4 & 11.3 & 12.1 \\
\hline$\beta_{6}$ & 2.9 & 11.7 & 13.8 & 10.4 & 15.9 & 12.3 \\
\hline$\beta_{7}$ & -2.8 & 11.4 & 9.4 & 9.9 & 16.1 & 12.0 \\
\hline$\beta_{8}$ & -0.6 & 10.7 & 6.4 & 9.0 & 10.1 & 11.2 \\
\hline$\beta_{9}$ & 7.2 & 11.0 & 1.9 & 9.2 & -3.7 & 11.3 \\
\hline \multirow[t]{2}{*}{$\begin{array}{l}\text { Test: }\left\{\beta_{s}\right\} \text { joint } \\
\text { significance }\end{array}$} & & .14 & & .15 & & .07 \\
\hline & \multicolumn{6}{|c|}{ Implied Long-Run Cumulative Effects } \\
\hline$b_{9}$ & 48.7 & 54.5 & 61.7 & 68.9 & 27.5 & 23.3 \\
\hline $\begin{array}{l}\text { Note. - This tabl } \\
\text { corresponding to tl } \\
\text { corresponding impl } \\
\text { reported } p \text {-values c } \\
\text { tests of the joint sigr } \\
\text { variables. The stanc } \\
\text { accounts. } \\
\text { * Significantly di } \\
\text { ** Significantly d }\end{array}$ & $\begin{array}{l}\text { ports the mar } \\
\text { indicator varia } \\
\text { long-run cum } \\
\text { from tests of } \\
\text { cance of the cu } \\
\text { errors are ac } \\
\text { ent from zero } \\
\text { rent from zero }\end{array}$ & $\begin{array}{l}\text { al effects } \beta_{s} \\
R_{t} \text { and its } \\
\text { tive effects, } \\
\text { e joint signif } \\
\text { lative effects } \\
\text { sted for hete } \\
\text { the } 10 \text { perce } \\
\text { the } 5 \text { perce }\end{array}$ & $\begin{array}{l}\text { receiving a rebat } \\
\text { ine lags, } R_{t-1} \text { to } \\
\text { All values are in } \\
\text { cance of the mar } \\
\text { to } b_{9} \text {.) Each regr } \\
\text { oscedasticity acro } \\
\text { t level. } \\
\text { t level. }\end{array}$ & $\begin{array}{l}\text { e, for each mo } \\
R_{t-9} \text {, in eq. (1 } \\
\text { current dolla } \\
\text { inal effects } \beta_{0} \\
\text { ession also incl } \\
\text { s accounts as }\end{array}$ & $\begin{array}{l}\text { h } s=0-9 \text { after } r \\
\text { The bottom rov } \\
\text { (March 2001-M } \\
\text { o } \beta_{9} \text {. (These are } \\
\text { les a full set of mo } \\
\text { ell as serial corr }\end{array}$ & $\begin{array}{l}\text { bate receipt, } \\
\text { reports the } \\
\text { 2002). The } \\
\text { equivalent to } \\
\text { nth indicator } \\
\text { lation within }\end{array}$ \\
\hline
\end{tabular}

study, with month 0 being the time of rebate receipt, $s=0$ in event time.

Starting with the point estimates for payments, in the month of rebate receipt, (monthly) payments rise by $\beta_{0}=\$ 12$ on average. One month after receipt, payments are still $\beta_{1}=\$ 11$ larger than before receipt (so $\left.b_{1}=\$ 23\right)$, but the subsequent marginal coefficients tend to decline in magnitude and significance (with only $\beta_{0}$ being significant at the 10 percent level or better). As is evident in the first graph, the path of cumulative payments plateaus after month 4 . Allowing for some time delay before consumers deposit their rebate check, make a larger payment to the issuer, and have that payment register on the monthly statement, the point estimates imply that, on average, consumers initially used some of the rebate to increase their credit card payments. The average long-run, cumulative increase in payments is $b_{9}=\$ 49$ (bottom of table 2).

As for spending, in the second graph in figure 1, the path of cumulative spending coefficients is initially flatter than the path for payments. But after month 2 the path for spending starts to rise faster, 

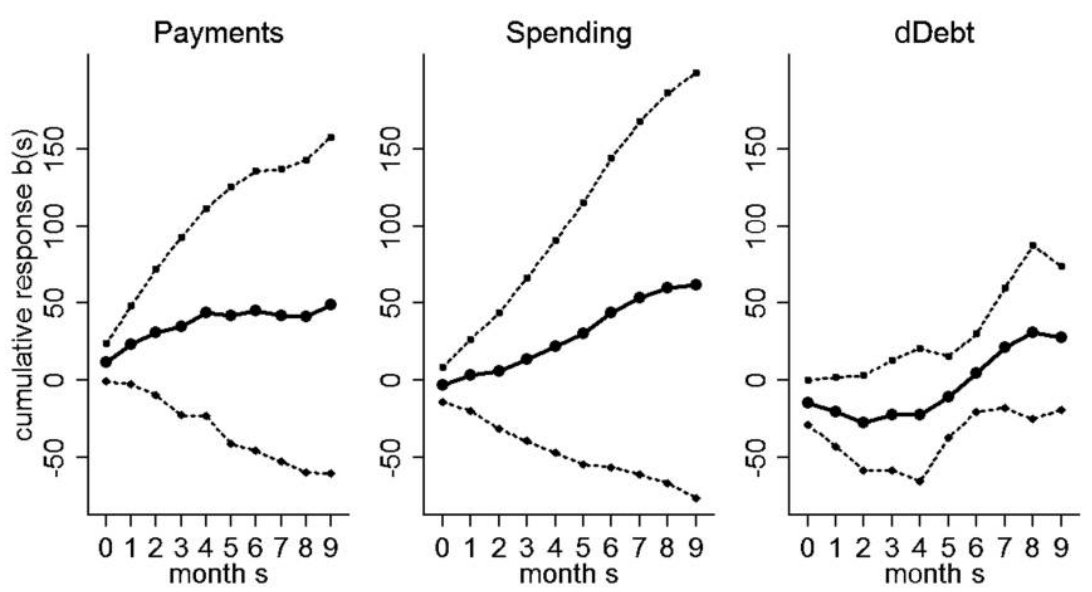

Fig. 1.-Consumer response to rebates: the cumulative responses $b_{s}$ in months $s=$ 0-9 after rebate receipt (as implied by the baseline results in table 2), along with their corresponding 95 percent confidence intervals (dashed lines), in current dollars.

overtaking the payments path after month 6 before plateauing. ${ }^{11}$ The average long-run, cumulative increase in spending is $b_{9}=\$ 62$, which corresponds to about 12 percent of the average household rebate. Although not statistically significant, this baseline cumulative effect, like the corresponding $b_{9}$ for payments, is economically significant, considering that it reflects only the average response per credit card account, not per account holder.

In general, the baseline results in table 2 are imprecisely estimated. In part this is due to the limited random variation we are using. Since estimating high-frequency, monthly responses to this variation is demanding of the data, the individual marginal coefficients are difficult to estimate with precision. By summing across these coefficients, the paths of cumulative effects for spending and payments are smoother, but nonetheless their significance levels need not necessarily increase with the horizon $(s)$. (For spending, the significance of the baseline cumulative coefficients does tend to increase with horizon, but only slowly.) This reflects the fact that the estimates of the underlying marginal coefficients tend to have positive covariance across horizons, which the standard errors for the cumulative coefficients take into account.

${ }^{11}$ The delay before spending starts to increase is further discussed below. It partly reflects the need for high-utilization account holders to first make payments before they can make additional purchases (in addition to the short delay before payments and spending register on the credit card statement), plus potentially other mechanisms, such as habits. Gross and Souleles (2002) found qualitatively similar dynamics in average credit card spending in the months after exogenous increases in credit limits. 
Even so, we shall see shortly that there are significant differences in response across different account holders and that allowing for heterogeneity yields more significant marginal and cumulative coefficients for certain types of account holders. ${ }^{12}$ Hence it is not surprising that the full-sample results, which assume similar responses across all account holders, are less significant.

The baseline results for payments and spending are reflected in the results for debt in the third graph of figure 1 . Since payments rise before spending, debt initially declines, significantly so in month 0 . The point estimates imply that debt subsequently increases, reflecting the lagged increases in spending. The estimated long-run change in debt $b_{9}$ is positive, but it is insignificant and small in magnitude (e.g., relative to average debt levels of almost $\$ 2,000)$, both here and in most of the subsequent analysis, so this particular result should not be overemphasized. ${ }^{13}$ Another way to assess the significance of the dynamics of debt and of the other variables is to test the joint significance of the entire set of marginal coefficients $\left\{\beta_{s} \mid s=0-9\right\}$, which is equivalent to testing the joint significance of the cumulative coefficients $\left\{b_{s} \mid s=0-9\right\} .{ }^{14}$ As reported near the bottom of table 2 , for debt the estimated coefficients are jointly significant at the 7 percent level, with the initial coefficient being the most significant. ${ }^{15}$

To illustrate more broadly the potential importance of such balance sheet dynamics, consider someone who receives a $\$ 600$ rebate and, as

\footnotetext{
${ }^{12}$ For instance, for many of the key sample split groups analyzed later in table 3 (e.g., for young, low-limit, high-utilization, high-usage, and the "composite-constrained" account holders), the significance levels of the cumulative coefficients for spending generally increase with the horizon more quickly than in table 2 , becoming statistically significant within the nine months after rebate receipt. Also, in table A1, the cumulative significance levels for both spending and payments generally increase in horizon for all four groups of rebate recipients, becoming significant within a few months after receipt.

${ }^{13}$ As evidenced by its relatively wide 95 percent confidence interval, which ranges from about $-\$ 19$ to $\$ 74, b_{9}$ for debt is insignificantly different from both zero and $b_{0}$ (and $b_{2}$, the most negative cumulative coefficient). Thus, while one cannot reject the hypothesis that debt reverts (zero long-run change), one also cannot reject the hypothesis that the initial decline in debt is permanent. Nonetheless, as discussed below, both hypotheses can be consistent with a significant increase in spending.

${ }^{14}$ The reason is that the partial sums $\beta_{0}, \beta_{0}+\beta_{1}, \ldots, \beta_{0}+\beta_{1}+\cdots+\beta_{9}$ are all zero if and only if the marginal coefficients $\beta_{0}, \beta_{1}, \ldots, \beta_{9}$ are all zero.

${ }^{15}$ To help further gauge the magnitudes of the results in table 2 and subsequent tables, table 1 reports the average levels and average monthly changes of payments, spending, and debt over the sample period. The dependent variables in eq. (1) also vary significantly over time, since the month indicator variables (relative to the omitted first month of the sample) are jointly significant in each of the three regressions in table 2 (for brevity, not reported). For payments, the estimated coefficients on the 14 month indicators range from $-\$ 19$ to $\$ 44$, for an intrasample swing of about $\$ 63$. For spending, all the month coefficients are positive, with the largest being about $\$ 103$; for the change in debt, the coefficients range from $-\$ 35$ to $\$ 88$, for a swing of about $\$ 123$. Note that the estimated $b_{9}$ 's in table 2 for spending and payments are sizable fractions of these intrasample swings. They are also sizable relative to the annualized average monthly changes in table 1 .
} 
a result, increases his total spending by the full $\$ 600$, using a credit card. Suppose that he uses the rebate proceeds to increase his credit card payments by $\$ 600$ to fully pay for the extra spending. In this case there would be no longer-run effect on debt (we ignore any small differences due to interest), even though spending fully responds to the rebate. If the extra payments precede the extra spending, debt will first decline but then recover. If instead spending partially responds to the rebate, but by less than the full $\$ 600$ in extra payments, then there would be a persistent decline in debt. Hence a persistent decline in debt is also consistent with an expansionary effect of spending (as long as debt does not decline by the full amount of the extra payments). As a result, since we can directly estimate the response of spending, we do not need a precise estimate of the long-run change in debt in order to gauge per se the expansionary effect of the rebate.

More generally, in the presence of significant spending dynamics, static specifications that allow for only an immediate spending response to the rebate would underestimate its full effect. In particular, without a flexible dynamic analysis, it would be difficult to identify a lagged response of spending to the extra liquidity arising after consumers initially save some of their rebate, whether by accumulating assets or paying down debt.

The distributed lag specification in table 2 accommodates the average monthly dynamics of the dependent variables in a very general way. As an extension, we undertake some intramonthly analysis, distinguishing account holders according to how early in the month (whether in July, August, or September) their rebate was disbursed, with week 1 being the first week in the month and week 4 being the last. For example, if (marginal) spending takes place roughly evenly over the month, we might be able to detect that the path of spending starts increasing slightly earlier on average for those receiving their rebates earlier in the month.

Since such intramonthly analysis is even more demanding of the data than the baseline analysis in table 2, we impose some additional structure for these results (and a few of the subsequent extensions). Note that, although the baseline estimation was totally nonparametric, the results turned out relatively well behaved. In particular, the baseline marginal coefficients for spending and payments are generally positive, and they generally decline in horizon for payments and are hump-shaped for spending. Consequently, the cumulative effects for payments and spending are generally increasing (nondecreasing) in the horizon, before eventually plateauing. To increase precision in the intramonthly specification, we impose a priori the constraint that the marginal responses of spending and payments be nonnegative: $\beta_{s} \geq 0$ for all $s$. In the simplest analysis, spending and payments should not in general decline in re- 
sponse to an increase in liquidity, so this should be a relatively minimal restriction. (By contrast, debt can decline, so we do not estimate this specification for debt. $)^{16}$

The resulting point estimates, reported in Appendix table A1, provide some rough indication that the increases in spending and payments begin slightly earlier for the early-in-the-month recipients (week 1) relative to the later-in-the-month recipients. However, these differences are not statistically significant, so these results are inconclusive. Further discussion of them is reserved for Appendix A. Not surprisingly, such intramonthly comparisons cannot be made with much precision. Nonetheless, many of the results are significant in absolute terms. Notably, for both payments and spending, and for all four weeks of receipt, the long-run cumulative effects $b_{9}$ are statistically and economically significant, even though they do not significantly differ across the weeks. Since the variation underlying these results for spending, as well as the other significant results for spending below, is randomized, the results imply a causal link from the rebate to spending, counter to the LCPI model.

We now turn to a comparison of how consumers of different demographic and credit characteristics responded to the rebate. Because it is difficult to simultaneously estimate separate responses by week of receipt for each of the different groups of account holders that we will examine, we return to our baseline monthly specification (without imposing the nonnegativity constraint). Table 3 reports the long-run, cumulative coefficients $b_{9}$ for each group, as well as $p$-values for the significance of these coefficients and of the corresponding coefficients at an intermediate horizon of five months $\left(b_{5}\right)$. Figure 2 graphs all the cumulative coefficients, across all horizons $s=0-9$, for payments, spending, and the change in debt in separate panels. For each regression, table 3 also reports the joint significance of the marginal coefficients (equivalently, the cumulative coefficients) separately for each group in the regression and also combined across all groups in the regression (under the label "combined test").

Panel A of table 3 starts with marital status. To equation (1) we added indicator variables for couples and singles and interactions of these variables with the rebate indicator and its nine lags. The results for

\footnotetext{
${ }^{16}$ While the cumulative responses should not be negative, some marginal coefficients could potentially go negative in some situations. For example, suppose that in response to the rebate someone purchases a large durable good. As a result, in some subsequent months spending could potentially end up lower than it would have been in the absence of this purchase. However, in the baseline results in table 2, few of the marginal coefficients for spending and payments are negative, and even then they are small in magnitude. Consistently, in table A1 the nonnegativity constraint binds in just a few cases (indicated by NA in the standard errors column). Also, Johnson et al. (2006) finds significant responses to the rebates only in nondurable expenditures (including apparel), not in expenditures on larger durables.
} 
spending appear in the second set of columns in table 3. As reported, spending by couples increases by somewhat more on average than spending by singles: by $b_{9}=\$ 74$ versus $b_{9}=\$ 61$ cumulatively over the nine months after rebate receipt, though neither result is statistically significant. Since the rebates that couples received were typically twice as large ( $\$ 600$ vs. $\$ 300)$, their moderately greater spending in dollar terms represents a smaller share of the rebates they received. The intermediate dynamics are displayed in figure 2 , in the first two columns of graphs (labeled with the prefix $A$ ). Singles initially increase their payments, such that their debt significantly declines in the month of receipt and further declines in the next two months (with the most negative cumulative debt coefficient being $b_{2}=-\$ 47$ [23]). However, as their spending later increases, the point estimates for debt subsequently increase and become insignificant. These dynamics are reflected in the joint significance of the singles' marginal coefficients for debt $(p$-value $=0.01$ in table 3$)$.

Panel B of table 3 instead considers age, contrasting young ( $<35$ years old), middle-aged, and older $(>60)$ account holders. For spending, the long-run cumulative responses $b_{9}$ decline monotonically with age. The spending of the young account holders increases on average by $b_{9}=$ $\$ 200$ cumulatively. This response is statistically and economically significant. It is also statistically significantly larger than the $b_{9}$ 's of each of the two groups of older account holders (despite the individual standard errors for each group). These results are suggestive of liquidity constraints, since the young are disproportionately likely to be constrained (Jappelli 1990). If one reestimates this specification adding the nonnegativity constraint $\beta_{s} \geq 0$ for all $s$, while the resulting $b_{9}$ remains significant and larger for the young, it is statistically significant for each of the older age groups as well. Moreover, even without the constraint, the reported $p$-value of 0.04 for the combined test of significance indicates that the marginal and cumulative coefficients for spending are jointly significant when all three age groups are considered together (i.e., considering all the coefficients $\left\{\beta_{s, a}\right\}$ for all ages $a$ and all horizons $s$ jointly). Thus, after we allow for heterogeneity in age, the coefficients for spending are jointly significant across the entire sample. Such results illustrate the importance of heterogeneity.

The coefficients for spending are not, however, jointly significant for the age groups separately, not even for the young whose $b_{9}$ is significant. While the young's cumulative spending coefficients start to increase in the first month after receipt, the increases (based on the underlying marginal coefficients and reflected in fig. 2) become consistently significant only after month 5 . (Nonetheless, the cumulative coefficient $b_{5}$, although insignificant itself, is already significantly larger than the $b_{5}$ for the older account holders, at the 6 percent level.) This lag in 


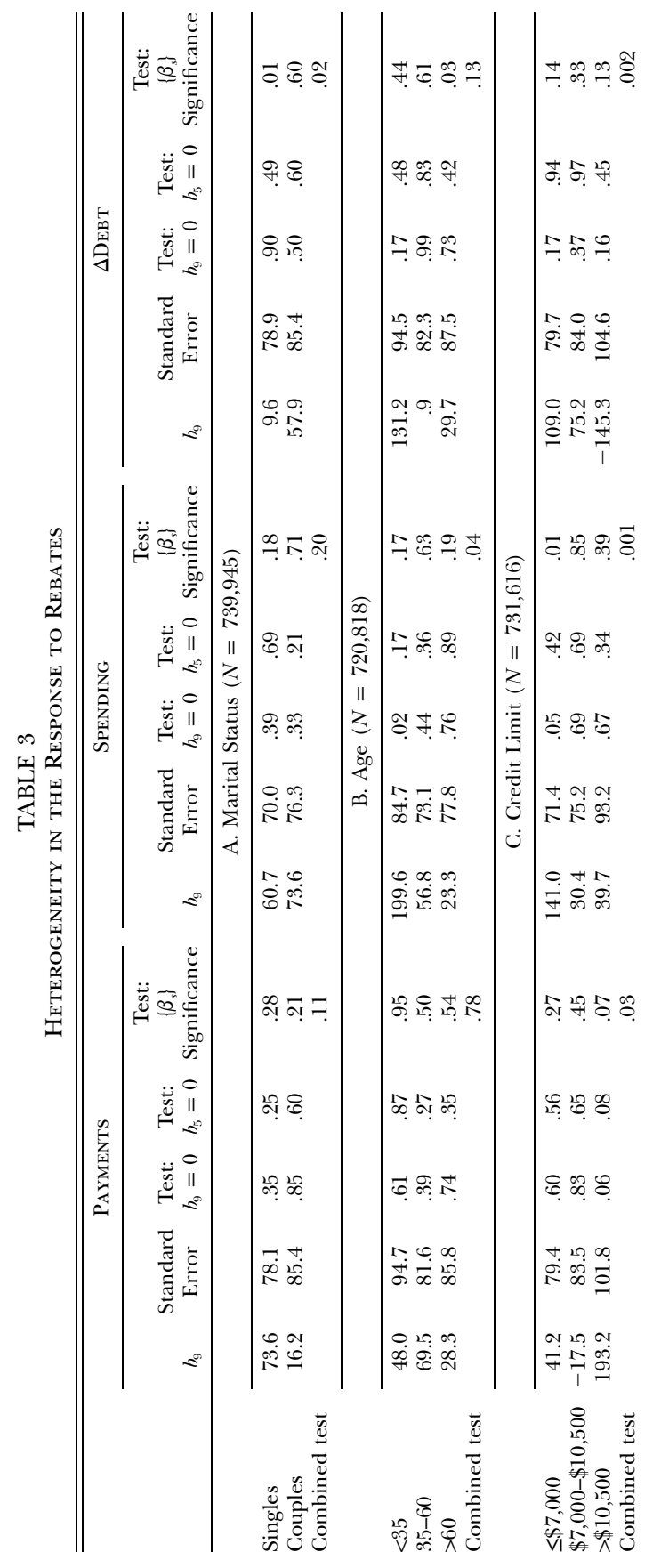

1000 


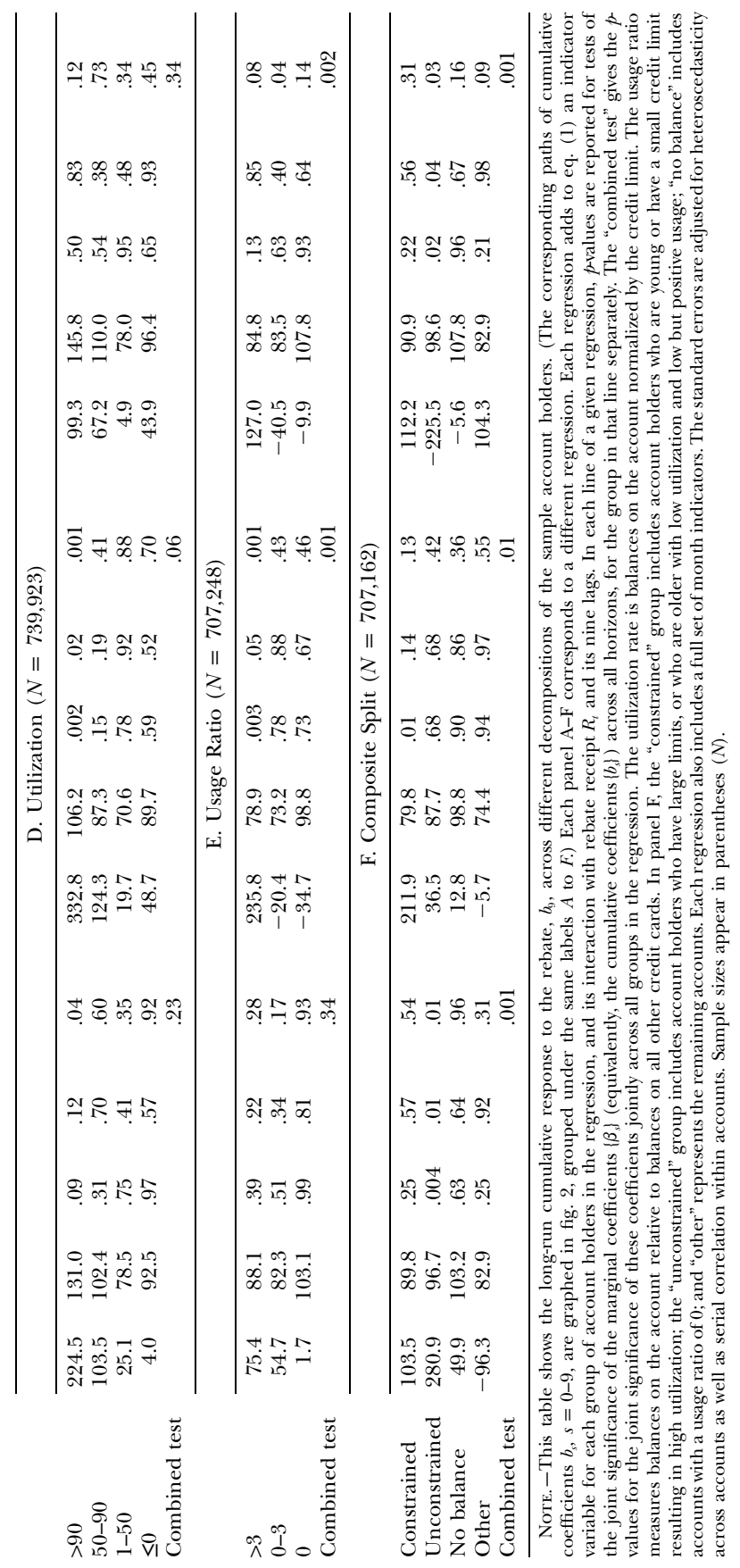

1001 


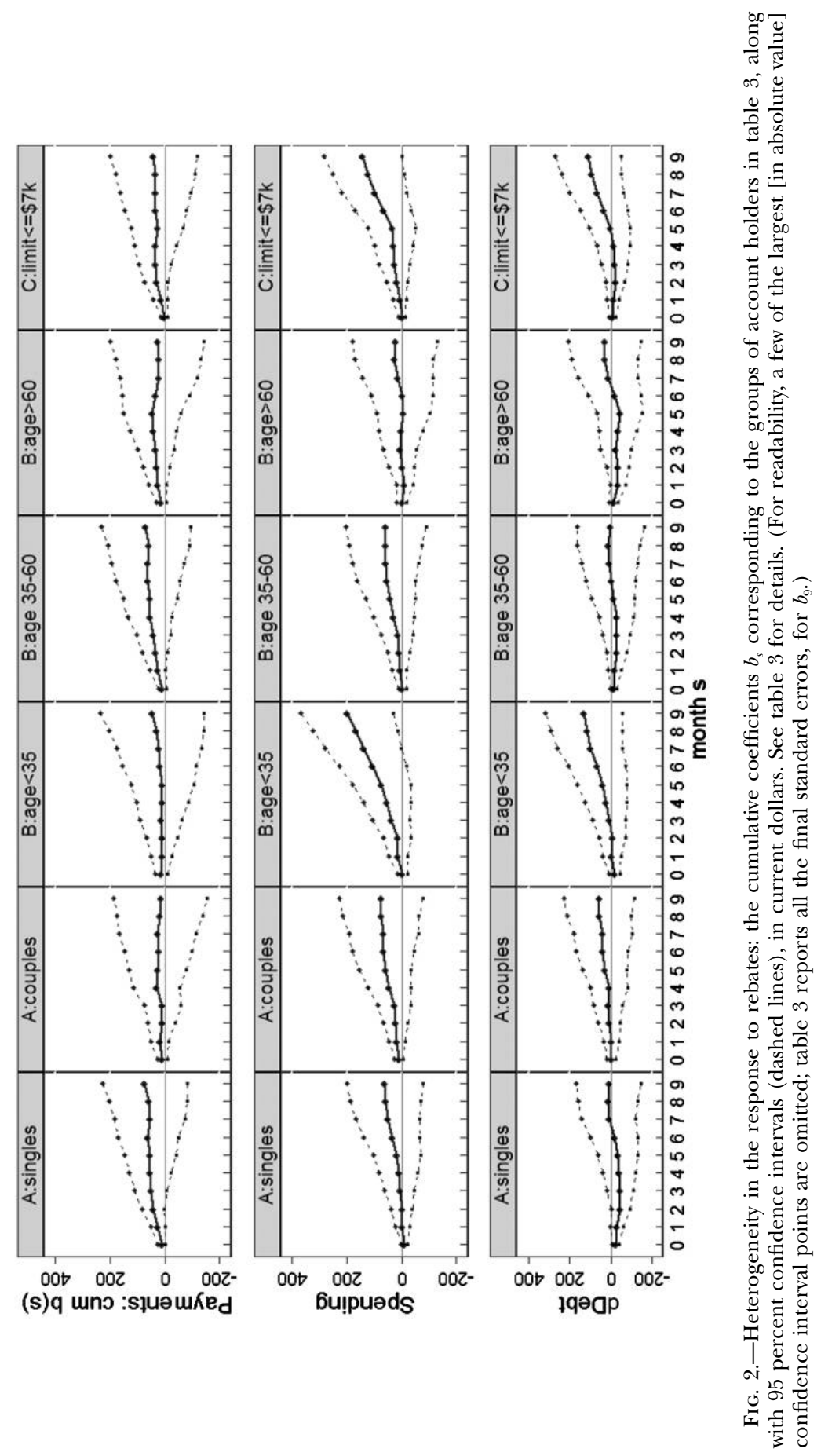

1002 

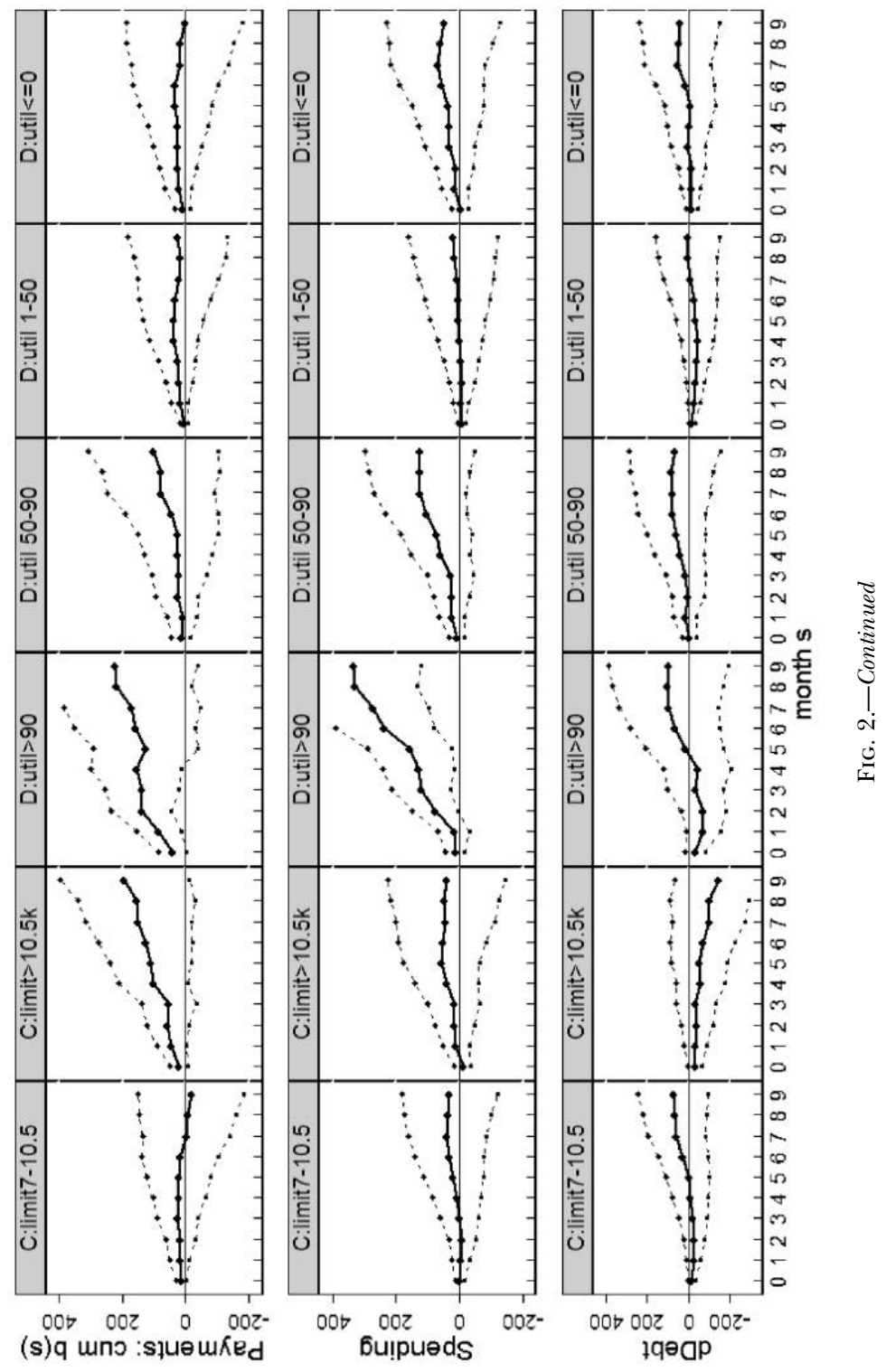

1003 


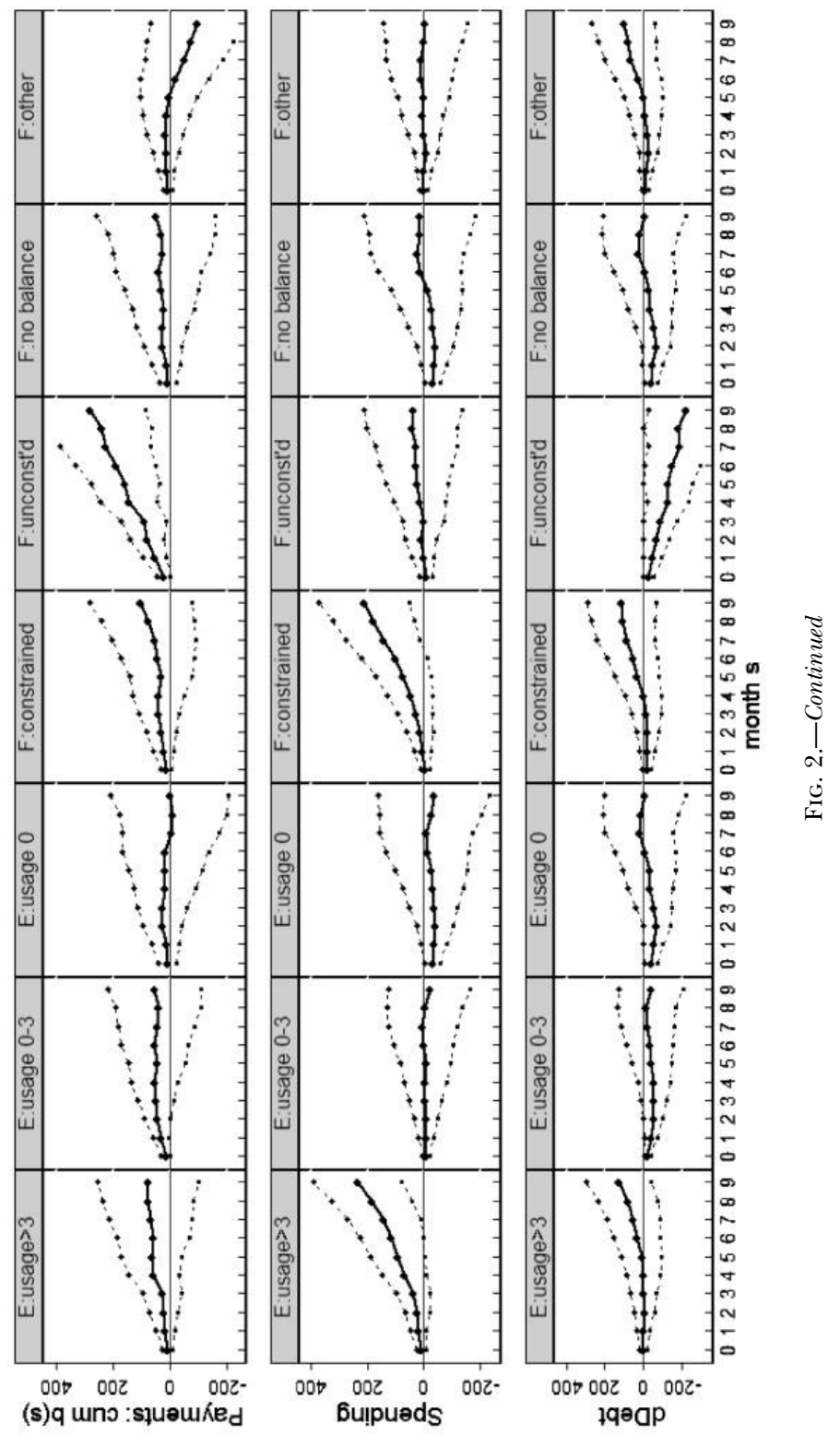


spending (both here and in later results below) can potentially be explained by a number of additional mechanisms, such as habits or other costs of adjusting consumption, precautionary motives (e.g., Carroll 1992), time to search and buy, or heterogeneous inattention (e.g., Reis 2006). ${ }^{17}$

By contrast, for older account holders (and, to a lesser extent, the middle-aged), the point estimates suggest more of an initial decline in debt, though this decline is not statistically significant and the point estimates subsequently increase. Nonetheless, in month 5 after receipt, their change in debt is still negative and (although insignificant itself) significantly different from that of the young, at the 7 percent level.

Our data allow for even more direct tests for liquidity constraints. One advantage of credit card data is that they separately record credit limits and credit balances. On average, consumers whose balances start near their limits are expected to be more likely to be liquidity constrained (Gross and Souleles 2002). Panel C of table 3 starts by considering the credit limit alone, since it is more exogenous than balances. (To further minimize any endogeneity, we lag the credit limits, taking them from month $t-9$, the start of the distributed lag horizon in eq. [1].) We divide the accounts into those with low credit limits $(\leq \$ 7,000)$, which constitute about two-fifths of the sample; intermediate limits, another two-fifths; and high limits $(>\$ 10,500)$, the remaining fifth. The low-limit accounts are most likely on average to actually be constrained by their limit. ${ }^{18}$

As expected, the low-limit accounts do exhibit the largest increase in spending. The long-run, cumulative increase is $b_{9}=\$ 141$. This response is economically and statistically significant and significantly larger than the $b_{9}$ of the intermediate-limit group. While the marginal spending coefficients for the low-limit group are jointly significant, the resulting

\footnotetext{
${ }^{17}$ As discussed below, Johnson et al. (2006) also finds a persistent response of consumption over the nine months after rebate receipt. The response is somewhat backloaded for certain categories of expenditure, such as apparel, which as noted is the largest contributor to the overall response of consumption and is relatively likely to be purchased using credit cards.

One should also keep in mind the relatively wide confidence intervals around the estimated coefficients at different horizons (as evident in fig. 2). This partly reflects the imprecision associated with nonparametric estimation, especially in the smaller effective samples for the various subgroups of accounts in table 3 . If one imposes the nonnegativity constraint $\beta_{s} \geq 0$ for all $s$, the results tend to be even more significant than those reported in table 3. For example, under the constraint, for the spending of the young, all the marginal coefficients, other than $\beta_{0}$ and $\beta_{2}$, are significant at the 10 percent level or better, and the corresponding cumulative coefficients are all significant after month 2 .

${ }^{18}$ For example, on average these accounts have the largest utilization rates. For the regressions that split the sample directly using the credit limit, we exclude the (relatively few) accounts with limits below $\$ 1,000$ to accommodate the typical rebates of $\$ 300-\$ 600$. This exclusion leads to slightly sharper but similar results when splitting using the limit, but has very little effect if applied to the baseline results.
} 
increase in spending is again back-loaded. On the basis of the point estimates, cumulative payments for this group initially increase faster than cumulative spending, so their debt initially declines. However, the decline in debt is insignificant and small in magnitude, and debt subsequently increases as spending later overtakes payments. ${ }^{19}$

By contrast, the high-limit accounts exhibit a substantial increase in payments, by almost $\$ 200$ cumulatively. This response is significant at the 6 percent level (and at the 5 percent level when the nonnegativity constraint is imposed). It is also significantly larger than the corresponding $b_{9}$ for the low-limit group (despite the individual standard errors for each group). However, the high-limit accounts do not show much change in spending. Consequently, their debt declines by $\$ 145$ by month 9 , a substantial amount. While this decline is imprecisely estimated, it is significantly different from the corresponding $b_{9}$ for the low-limit group. Thus, the high-limit account holders, who were expected most likely to be unconstrained, are in fact more likely to save their rebates by paying down debt. Their response is more consistent with the LCPI model. The contrast between this response and the substantial increase in spending by the low-limit account holders suggests that the latter are indeed relatively likely to be liquidity constrained (with the noted qualification about the back-loading of their spending).

Panel D of table 3 groups accounts according to their initial utilization rate, defined as the ratio of balances to the credit limit. While low-limit account holders are relatively likely to be constrained by their limit, using utilization directly should be even more likely to identify the account holders whose limits are actually binding, and so should yield sharper results. ${ }^{20}$ To minimize endogeneity, utilization is taken from month $t-9$.

Almost 10 percent of the accounts have utilization rates above 90 percent. For them liquidity constraints are most likely on average to be binding. In fact, as reported the cumulative increase in their spending

\footnotetext{
${ }^{19}$ We shall see shortly that part of the explanation for these dynamics appears to be that account holders who start with high utilization rates first need to make payments before they can increase spending. For high-utilization accounts, the initial rise in spending takes place very soon after the initial rise in payments, so that the rise in spending is relatively more front-loaded (less back-loaded) than for other groups. Since the other groupings of potentially constrained accounts, such as low-limit accounts, are not perfectly correlated with the high-utilization accounts, this relative front-loading gets attenuated for the other groupings.

${ }^{20}$ For example, Gross and Souleles (2002) found that, for credit card accounts with high utilization rates (above 90 percent), spending sharply rises after increases in liquidity caused by increases in credit limits, significantly more than for lower-utilization accounts. These results, which split the sample using utilization directly, are sharper than analogous results using other indicators of liquidity constraints, such as age. Other credit bureau data suggest that account holders who have high utilization rates on a given credit card also tend to have high utilization rates on their other cards and so high total credit card utilization rates at the account holder level.
} 
is a substantial $b_{9}=\$ 333$. This response is statistically significant and also significantly larger than the $b_{9}$ 's of each of the groups with lower utilization. For the high-utilization accounts, the marginal coefficients for spending are jointly very significant $(p$-value $=.001)$, and many of the individual coefficients are large and significant, starting in the second month after receipt. Accordingly, starting in month 2, all the cumulative coefficients are significant. As evident in figure 2, for this group the response of spending is relatively sharp and less back-loaded than the previous results for the young and low-limit groups.

Since the high-utilization account holders started near their limits, how can they substantially increase their spending? They first make large initial payments in order to create liquidity in terms of available credit. Indeed, for this group the marginal coefficients for payments are jointly significant, with the initial coefficients $\beta_{0}$ through $\beta_{2}$ being especially large and significant (at the 5 percent level for $\beta_{2}$ ). ${ }^{21}$ The cumulative $\$ 225$ increase in payments is substantial and significant at the 10 percent level. Overall, the results for the high-utilization group are indicative of binding liquidity constraints.

As for the other groups in panel D of table 3, the accounts with lower utilization rates-of 50-90 percent, 1-50 percent, and zero-constitute about 20 percent, 60 percent, and 10 percent of the sample, respectively. For the accounts with 50-90 percent utilization, the estimated $b_{9}$ for spending is still substantial in magnitude, albeit insignificant and smaller than for the high-utilization group. This is consistent with the idea that the intermediate-utilization accounts face a material, albeit smaller, probability of being constrained..$^{22}$ Their debt does not decline in the months after receipt (apart from a tiny coefficient $b_{0}=-\$ 4$ for month $0)$. By contrast, for the accounts with positive but small utilization (1-

\footnotetext{
${ }^{21}$ As seen in the paths for payments and spending in fig. 2, the initial rise in payments resembles the initial rise in spending shifted one month earlier. Thus debt declines in months 0 and 1 , with $b_{1}=-\$ 71$ (41) being significant at the 10 percent level. But subsequently the point estimates for debt increase and become insignificant. Account holders who start constrained by their credit card limit could of course spend their rebate without using their credit card. But if for various reasons (e.g., convenience, safety, perks, etc.) they prefer to use their card for their marginal spending (e.g., on apparel), then they need to first increase their payments.

${ }^{22}$ Gross and Souleles (2002) also found an intermediate response to liquidity by accounts with utilization rates of 50-90 percent. They note that this response is consistent with models with precautionary motives, in which liquidity constraints matter even if they do not currently bind, as long as there is a possibility that they bind in the future. Our utilization cutoffs are based on those in the Gross and Souleles article, but of course the particular cutoffs are somewhat arbitrary. In general, the tighter the cutoff, the more likely the resulting group includes consumers with a high probability of being constrained. If we tighten the definition of the second utilization group to 60-90 percent utilization, the resulting $b_{9}$ becomes larger (though it remains smaller than the $b_{9}$ for those with utilization above 90 percent) and significant at the 6 percent level. About 20 percent of the sample accounts have utilization above 60 percent.
} 
50 percent), debt significantly declines in the month of receipt. Although the later point estimates are insignificant, they continue to decline through month 4 (with $b_{4}=-\$ 42$ [40]) before subsequently increasing. Regarding the accounts that start with zero utilization (and so no balances), one might expect them to be relatively less likely to respond at all to the rebate. Indeed, their results suggest little response. Their cumulative coefficients are all relatively small in magnitude and insignificant, with somewhat larger confidence intervals because of the smaller sample size. These results might be thought of as characterizing, in a sense, the amount of underlying noise in the data.

The average household has over two credit cards (1995 SCF), so by estimating at the account level, we have so far probably understated the full effect of the rebate per account holder. As a starting point we could look at account holders who have only one credit card in total-the card in our sample-but they are probably not representative. However, one can generalize the notion of having only one card, since consumers with multiple cards can choose to concentrate their usage on a subset of their cards. As one way of measuring the relative intensity of usage of the card in our sample, we define the "usage ratio" as balances on the sample account relative to all other credit card balances held by the account holder, based on the most recent credit bureau data. Consumers with a large usage ratio are relatively intensive users of the accounts in the sample. If the intensively used accounts tend to be the marginal accounts in terms of spending, then these accounts would be expected to respond the most to the rebate, and vice versa. ${ }^{23}$

Panel $\mathrm{E}$ of table 3 distinguishes accounts with usage ratios of above $3,0-3$, and 0 (approximately 30 percent, 60 percent, and 10 percent of the sample, respectively), taking the usage ratio from month $t-9$ to minimize endogeneity. Starting with the high-usage ratio accounts, their spending increases by over $\$ 200$ cumulatively. This response is statistically and economically significant, corresponding to over 40 percent of the average household rebate. The response is also significantly larger than that of the accounts with a usage ratio of $0 .{ }^{24}$ For the high-usage accounts, the underlying marginal coefficients for spending are also jointly very significant $(p$-value $=.001)$. The resulting path of cumulative spending coefficients is somewhat back-loaded, but nonetheless the coefficients are significant by month 5 (as reported) and subsequently.

\footnotetext{
${ }^{23}$ To illustrate the opposite case, suppose that after consumers put significant balances on one account, they use their other accounts with smaller balances for their marginal spending. Then the latter accounts might respond the most to the rebate. This case is not, however, supported by the results below.

${ }^{24}$ The results based on the number of credit cards held are consistent: Consumers who also have other credit cards (outside the sample) spend less on their account in the sample than consumers who do not have other cards.
} 
By contrast, for the middle-usage accounts, the point estimates show little change in spending and a moderate increase in payments, and so a moderate decline in debt. This decline is significant in the first few months, and while it subsequently becomes less significant, it is relatively persistent, with $b_{9}=-\$ 41 .^{25}$ Regarding the accounts with a usage ratio of 0 , they generally show little response to the rebate, like the accounts with zero utilization. ${ }^{26}$

Finally, building on the previous results, panel $\mathrm{F}$ of table 3 utilizes a composite sample split that uses multiple characteristics to distinguish account holders who are relatively likely to be constrained from those who are relatively likely to be unconstrained. The composite split identifies potentially constrained account holders (labeled as "constrained" in the table) as those who are young ( $\leq 35$ years old) or have a small credit limit $(\leq \$ 7,000)$ that is relatively likely to be binding because of high utilization (above 60 percent). This group is expected to increase spending the most. The potentially "unconstrained" group includes account holders who have large limits $(>\$ 10,500)$, or who are older $(>55$ years old) with low utilization (below 40 percent) and low but positive usage (usage ratio between 0 and 0.4 ). This group is expected to increase payments and reduce debt the most. The composite split puts accounts with a usage ratio of 0 into a separate group (labeled "no balance"), which is expected to show relatively little response to the rebate. These three groups constitute about 25 percent, 25 percent, and 10 percent of the sample, respectively. The remaining, harder to classify, 40 percent of accounts are grouped together as "other."

\footnotetext{
${ }^{25}$ For the middle-usage accounts, the $b_{9}$ for payments becomes significant when the nonnegativity constraint is imposed. The decline in their debt becomes more pronounced if one restricts the group to accounts with a usage ratio between 0 and 0.4 , which is approximately the median ratio. Accordingly, this modified cutoff is used in the composite split in panel $\mathrm{F}$ of table 3 .

${ }^{26}$ One small difference between these groups is that the lowest-utilization group includes the (relatively few) accounts with negative utilization (e.g., due to overpayment or returns), whereas the usage ratio drops observations with negative balances. The point estimates for the group with a usage ratio of 0 show a moderate initial decline in debt. However, this is driven by an (implausible) estimated decline in spending, but this decline is small in magnitude and insignificant after the month of receipt.

${ }^{27}$ Some of the cutoffs used in defining these groups were slightly relaxed relative to the cutoffs in the previous "univariate" splits based on a single characteristic, in order to keep the composite groups from getting too small. Previous notes commented on some of these modifications. For example, accounts with utilization between 60 percent and 90 percent show a significant increase in spending (at the 6 percent level), albeit smaller than for accounts with utilization above 90 percent. We also considered some even more expansive cutoffs. In general, we could expand the size of the composite-constrained group and still find a significant, albeit smaller, increase in spending. Presumably the reason is that such expansions tend to include in the group more accounts with a smaller probability of being constrained. By contrast, we were unable to expand the unconstrained group by much and still find a significant decline in debt. As before, the characteristics used to form the groups are taken from month $t-9$ to minimize endogeneity.
} 
Beginning with the potentially constrained account holders, as reported, spending significantly increases, by a cumulative $b_{9}=\$ 212$. This response is statistically and economically significant and significantly larger than that of each of the three other groups. The response is again somewhat back-loaded. According to the point estimates, payments initially increase faster than spending, leading to a small initial decline in debt (though the cumulative coefficients for payments are all insignificant, and for debt only $b_{0}$ is significant at the 10 percent level or better). Debt subsequently increases, however, as spending later overtakes payments. By contrast, for the potentially unconstrained account holders, payments significantly increase, by a substantial cumulative amount $b_{9}=\$ 281$. This response is statistically significant and significantly larger than the corresponding $b_{9}$ for the constrained group. Many of the initial marginal payment coefficients for the unconstrained group are significant, so all their cumulative coefficients after the month of receipt are significant (and even the immediate response $b_{0}$ is significant at the 10 percent level). On the other hand, their spending increases by a much smaller and insignificant amount. Hence their debt persistently decreases, by a substantial amount $b_{9}=-\$ 226$, which is statistically significant.

Overall, the results for these two groups are qualitatively similar to, but sharper than, the results for the corresponding groups in panel $\mathrm{C}$ of table 3 using just the limit. Hence, subject to the same qualifications, the results again suggest that liquidity constraints are indeed more likely to be binding for the account holders who were identified as constrained. Conversely, the account holders identified as unconstrained behave more consistently with the LCPI model. More generally, these results, along with the other results in table 3 , show that there is significant heterogeneity in the response of different consumers to the rebates.

We briefly turn to the remaining groups in panel $\mathrm{F}$. The results for the "no balance" group are like those in panel E for the group with a usage ratio of 0 . For the "other" group, the cumulative coefficients are all insignificant. ${ }^{28}$

As an extension, we also directly examined the response of the account holders' other credit cards, using the credit bureau data. In sum, the response of balances on the other cards is qualitatively similar to that of balances on the accounts in the main sample, so these results generally reinforce (or at least do not offset) our previous results. How-

\footnotetext{
${ }^{28}$ The point estimates for the "other" group show an (implausible) late decline in cumulative payments, but these estimates are not statistically significant. The results for the "no balance" group are not exactly identical to those for the group with a usage ratio of 0 in panel $\mathrm{E}$ because of differences in the other groups used in the two regressions (e.g., due to different missing values).
} 
ever, the estimates are insignificant, and so the results are inconclusive. Identification of the response of other balances is complicated by the fact that the credit bureau data are available only quarterly. Accordingly, further discussion of these results is reserved for Appendix B, with the results appearing in table B1.

\section{Related Literature}

A few previous papers have studied consumers' response to tax rebates and refunds. Modigliani and Steindel (1977), Blinder (1981), and Poterba (1988) found that consumption responded too much to the 1975 tax rebate, relative to the prediction of the LCPI model, though they came to somewhat different quantitative conclusions regarding the timing and overall magnitude of the response. All three studies used aggregate time-series data, but there are a number of advantages to using micro-level data as well. First, it is difficult to analyze infrequent events such as tax cuts using time-series data. ${ }^{29}$ Second, with micro data one can use cross-sectional variation to investigate consumer heterogeneity, including issues such as liquidity constraints. Among recent studies using micro data, one of the most closely related to this article is Souleles (1999), which found that consumption responds significantly to the federal income tax refunds that most taxpayers receive each spring. That paper also found evidence of liquidity constraints. ${ }^{30}$

Two recent papers analyzed the response to the 2001 tax rebates in particular. First, as noted in the introduction, Shapiro and Slemrod (2003a) found that the majority of their survey respondents reported that they would mostly save their rebate, most commonly by paying down debt. Only 22 percent of the respondents reported that they would mostly spend their rebate, a finding the authors calculate to imply an average marginal propensity to consume of about one-third. These results are consistent with our finding that, on average, consumers initially used some of the rebate to increase their credit card payments and pay down debt. The Michigan survey results provide no evidence, however,

\footnotetext{
${ }^{29}$ Blinder and Deaton (1985) found smaller consumption responses when considering the 1975 rebate together with the 1968-70 tax surcharge. However, consumption was found to be too sensitive to the preannounced changes in taxes in the later phases of the Reagan tax cuts. The authors note that their mixed results are "probably not precise enough to persuade anyone to abandon strongly held a priori views" (498).

${ }^{30}$ Other related studies of the response of consumption to income include Bodkin (1959), Kreinin (1961), Wilcox (1989, 1990), Parker (1999), Souleles (2000, 2002, 2004), Browning and Collado (2001), Hsieh (2003), and Stephens (2003, 2005, 2006), among others.
} 
of a lagged response of spending or of liquidity constraints. ${ }^{31}$ Second, a concurrent paper by Johnson et al. (2006) finds, using the Consumer Expenditure Survey, that consumers spent on average about a third of their rebates during the three-month period in which they were received, counter to the LCPI model. This finding implies that consumers initially saved most of the rebate, though their data do not allow the authors to distinguish whether the saving took place by paying down debt or by accumulating assets. Moreover, they also find significant evidence of a substantial lagged consumption response over the next two quarters, with the long-run cumulative response being roughly twothirds of the rebate on average. Illiquid households exhibited the strongest response. Despite the differences between consumption expenditure and credit card spending, these results are broadly consistent with the dynamics of credit card usage we estimated above. ${ }^{32}$

\section{Conclusion}

This article used a unique, new panel data set of credit card accounts to analyze how consumers responded to the 2001 federal income tax rebates. We used distributed lag models to estimate the month-by-month response of credit card payments, spending, and debt to the rebates, exploiting the randomized timing of the rebates' disbursement to cleanly identify their causal effects. By limiting ourselves to the subset of potential variation that is by construction exogenous, we set a high hurdle for finding significant effects of the rebate.

We found that, on average, consumers initially saved some of the rebate, by increasing their credit card payments and thereby paying down debt and increasing their liquidity. But soon afterward their spending increased, counter to the canonical LCPI model and Ricardian equivalence. For consumers whose most intensively used credit card account is in the sample, spending on that account rose by over $\$ 200$ cumulatively over the nine months after rebate receipt, which represents over 40 percent of the average household rebate. Because these results

\footnotetext{
${ }^{31}$ McNees (1973) analyzed similar surveys of refund recipients in 1972. Of his sample, 45 percent said they spent their refund, 24 percent saved it, and 28 percent used it to pay off debt and bills. Shapiro and Slemrod (1995) analyzed a similar survey after the change in withholding rates in 1992. Shapiro and Slemrod (2003b) used a novel followup survey in 2002 to try to determine whether there was a lagged response to the 2001 rebate. Of the survey respondents who said they initially mostly used the rebate to pay down debt, most report that they will "try to keep [down their] lower debt for at least a year" (96).

${ }^{32}$ While our results do not use aggregate time-series variation, they are also consistent with the aggregate data on consumption expenditure and saving discussed by Johnson et al. (2006). Aggregate spending rose substantially in the three quarters during and after which the rebates were disbursed, whereas the saving rate rose substantially in the quarter of disbursement, but then dropped in the next quarter.
} 
relied exclusively on exogenous, randomized variation, they represent compelling evidence of a causal link from the rebate to spending.

We also found other significant heterogeneity in the response to the rebate across different types of consumers. Notably, spending rose most for consumers who, according to various criteria, were initially most likely to be liquidity constrained-by up to over $\$ 300$ depending on the criterion and its tightness. By contrast, debt declined most (so saving rose most) for unconstrained consumers. These results suggest that liquidity constraints are important. More generally, the results suggest that there can be important dynamics in consumers' response to "lumpy" increases in income such as tax rebates, working in part through balance sheet (liquidity) mechanisms.

\section{Appendix A}

\section{Intramonthly Analysis}

Table A1 reports the results of the intramonthly analysis described in Section IV. As noted, the point estimates in the table provide some rough indication that the increases in spending and payments begin slightly earlier for the earlyin-the-month recipients relative to the later-in-the-month recipients: The initial marginal coefficients $\beta_{0}$ are somewhat larger for the recipients in week 1 relative to the other recipients, though these coefficients are not fully monotonic across the weeks of receipt. Also, these differences in month 0 are not statistically significant, and jointly across all horizons the paths of spending and of payments do not significantly differ across the weeks. ${ }^{33}$ Nonetheless, many of the results are significant in absolute terms. For spending, for all four weeks, many of the marginal effects at intermediate horizons are significant. Thus the cumulative effects become significant within a few months (for brevity, not reported). For both payments and spending, and for all four weeks, the long-run cumulative effects $b_{9}$ are statistically and economically significant (bottom of table A1), even though they do not significantly differ across the weeks. ${ }^{34}$

The intermediate dynamics are qualitatively similar to those in table 2 . For

${ }^{33}$ To test for such differences, we created three indicator variables for accounts whose rebates were disbursed in the first three weeks of the month (whether in July, August, or September) and added them and their interactions with $R$ and all its lags to eq. (1), omitting the fourth week. (Note, however, that table Al reports the implied total effects for each group, not the differences relative to week 4.) For each week 1-3 and each of spending and payments, the interaction terms are jointly insignificant. The interaction terms are also jointly insignificant when considered jointly across all three weeks together, for each of spending and payments.

${ }^{34}$ While the initial responses of payments and spending can differ across early- vs. latein-the-month recipients, the long-run responses should not significantly differ. As just noted, they do not. For comparison, distinguishing the week of receipt without imposing the nonnegativity constraint yields substantially less precise results than in table A1: $b_{9}=\$ 122$ (93), $\$ 15$ (97), $\$ 63$ (89), and \$1 (91) for payments for weeks 1-4, respectively; $b_{9}=\$ 129(84), \$ 9(89), \$ 115(80)$, and $\$ 73$ (82) for spending across weeks $1-4$; and $b_{9}=\$ 31(93), \$ 11(99), \$ 67(91)$, and $\$ 69$ (95) for debt across weeks $1-4$. We also tried constraining the marginal coefficients in table A1 to lie on a low-order polynomial, but in general this did not help increase precision much. 
TABLE A1

Consumer Response to Rebates: Intramonthly Analysis $(N=739,945)$

\begin{tabular}{|c|c|c|c|c|}
\hline & \multicolumn{2}{|c|}{ Payments } & \multicolumn{2}{|c|}{ SPENDING } \\
\hline & Coefficient & Standard Error & Coefficient & Standard Error \\
\hline \multicolumn{5}{|c|}{ Week 1: } \\
\hline$\beta_{0}$ & 22.3 & $9.3^{* *}$ & 9.1 & 7.7 \\
\hline$\beta_{1}$ & 15.8 & $9.7 *$ & 15.4 & $9.1^{*}$ \\
\hline$\beta_{2}$ & 30.1 & $10.3^{* *}$ & 28.9 & $9.5^{* *}$ \\
\hline$\beta_{3}$ & 19.3 & $10.5^{*}$ & 27.5 & $10.2 * *$ \\
\hline$\beta_{4}$ & 26.6 & $11.1 * *$ & 10.6 & 11.4 \\
\hline$\beta_{5}$ & 23.9 & $11.6^{* *}$ & 19.8 & $11.8^{*}$ \\
\hline$\beta_{6}$ & 12.0 & 11.3 & 32.6 & $11.7 * *$ \\
\hline$\beta_{7}$ & 13.0 & 11.0 & 24.3 & $10.6^{* *}$ \\
\hline$\beta_{8}$ & 7.0 & 10.7 & 13.8 & 9.3 \\
\hline$\beta_{9}$ & 29.3 & $13.8^{* *}$ & 9.6 & 10.4 \\
\hline \multicolumn{5}{|c|}{ Week 2: } \\
\hline$\beta_{0}$ & 18.0 & $10.7 *$ & .0 & NA \\
\hline$\beta_{1}$ & 13.8 & 11.0 & 8.2 & 9.4 \\
\hline$\beta_{2}$ & 9.9 & 11.2 & .0 & NA \\
\hline$\beta_{3}$ & 5.2 & 11.5 & 15.2 & 10.7 \\
\hline$\beta_{4}$ & 15.0 & 12.2 & 25.0 & $12.4^{* *}$ \\
\hline$\beta_{5}$ & 9.0 & 12.5 & 21.8 & $12.3 *$ \\
\hline$\beta_{6}$ & 24.7 & $13.0 *$ & 18.0 & 11.6 \\
\hline$\beta_{7}$ & .0 & NA & 13.9 & 10.3 \\
\hline$\beta_{8}$ & .0 & NA & .0 & NA \\
\hline$\beta_{9}$ & 6.1 & 16.3 & .0 & NA \\
\hline \multicolumn{5}{|c|}{ Week 3: } \\
\hline$\beta_{0}$ & 2.6 & 8.3 & 1.3 & 7.7 \\
\hline$\beta_{1}$ & 14.6 & 9.4 & 13.6 & $8.3^{*}$ \\
\hline$\beta_{2}$ & 1.4 & 9.4 & 7.9 & 9.2 \\
\hline$\beta_{3}$ & 19.7 & $10.1^{* *}$ & 19.6 & $9.6^{* *}$ \\
\hline$\beta_{4}$ & 25.2 & $10.3^{* *}$ & 22.8 & $10.5^{* *}$ \\
\hline$\beta_{5}$ & 10.2 & 10.6 & 17.5 & 11.2 \\
\hline$\beta_{6}$ & 30.7 & $11.6^{* *}$ & 33.3 & $11.4^{* *}$ \\
\hline$\beta_{7}$ & 17.2 & 11.0 & 19.7 & $10.3^{*}$ \\
\hline$\beta_{8}$ & 8.0 & 10.4 & 26.4 & $9.5^{* *}$ \\
\hline$\beta_{9}$ & 7.9 & 12.2 & 11.0 & 10.5 \\
\hline \multicolumn{5}{|c|}{ Week 4: } \\
\hline$\beta_{0}$ & 14.4 & 10.1 & .0 & NA \\
\hline$\beta_{1}$ & 18.1 & $10.6^{*}$ & 13.6 & 9.2 \\
\hline$\beta_{2}$ & 14.7 & 10.7 & 7.0 & 10.4 \\
\hline$\beta_{3}$ & .0 & NA & 7.8 & 10.6 \\
\hline$\beta_{4}$ & 6.0 & 10.7 & 24.0 & $11.8^{* *}$ \\
\hline$\beta_{5}$ & .0 & NA & 22.6 & $13.0^{*}$ \\
\hline$\beta_{6}$ & -.1 & 12.1 & 15.8 & 12.9 \\
\hline$\beta_{7}$ & 10.3 & 12.6 & 27.5 & $12.3^{* *}$ \\
\hline$\beta_{8}$ & 21.7 & $12.9 *$ & 18.6 & 11.5 \\
\hline$\beta_{9}$ & 6.8 & 12.0 & 12.1 & 10.1 \\
\hline
\end{tabular}


TABLE A1

(Continued)

\begin{tabular}{|c|c|c|c|c|}
\hline & \multicolumn{2}{|c|}{ Payments } & \multicolumn{2}{|c|}{ SPENDING } \\
\hline & Coefficient & Standard Error & Coefficient & Standard Error \\
\hline & \multicolumn{4}{|c|}{ Implied Long-Run Cumulative Effects $b_{9}$} \\
\hline Week 1 & 199.4 & $60.6 * *$ & 191.3 & $64.7 * *$ \\
\hline Week 2 & 101.6 & $51.6^{* *}$ & 102.2 & $40.9 * *$ \\
\hline Week 3 & 137.4 & $59.2 * *$ & 173.1 & $62.6^{* *}$ \\
\hline Week 4 & 91.9 & $44.9 * *$ & 149.0 & $62.4 * *$ \\
\hline Test: $\left\{\beta_{s}\right\}$ joint significance & & .27 & & .60 \\
\hline
\end{tabular}

NotE. - This table reports the marginal effects $\beta_{s}$ depending on the week within the month the rebate was received. Week 1 represents account holders who received their rebates in the first week of a month (whether July, August, or September 2001), and week 4 represents rebates received in the last week. The specification adds to eq. (1) an indicator variable for each week and its interaction with rebate receipt $R_{t}$ and its nine lags. The specification also includes a full set of month indicators. The marginal coefficients are constrained to be nonnegative, $\beta_{s} \geq 0$ for all $s$. (The cases in which the constraint binds are identified by NA in the standard errors column.) The reported $p$-values are from tests of the joint significance of the marginal coefficients $\{\beta\}$ jointly across all four weeks combined. The standard errors are adjusted for heteroscedasticity across accounts as well as serial correlation within accounts.

* Significantly different from zero at the 10 percent level.

** Significantly different from zero at the 5 percent level.

most of the weeks of receipt, the point estimates suggest that payments begin to increase before spending (less so in week 3), but soon afterward spending increases faster, such that the point estimates for $b_{9}$ for spending are generally similar in size or larger than the $b_{9}$ estimates for payments. However, given the statistical uncertainty around the estimated $b_{9}$ 's for spending and payments, one cannot make from these results strong inferences about their implications for the long-run change in debt, since the latter depends on the difference between the former.

\section{Appendix B}

\section{Balances on Other Credit Cards}

Table B1 analyzes the response of the account holders' other credit cards, using the credit bureau data. Because the credit bureau data on other balances are available only quarterly, we cannot identify the average response of these balances over time separately from month indicator variables. ${ }^{35}$ Nonetheless, we can still examine whether, in any given month of data, the other balances are larger for account holders who received their rebates earlier (i.e., in July and August 2001) than for those who received their rebates later (in September 2001).

To interpret the results in the table, note that other balances are available in four months of the sample (June, September, and December 2001 and March 2002), and the specification includes the corresponding month indicators. When $R_{t}$ is omitted, the independent variable $R_{t-1}$ (or $R_{t-2}$ ) then measures how much larger or smaller are the balances in September 2001 of those who received

${ }^{35}$ For example, since the rebates were disbursed in July, August, and September 2001, in the credit bureau data from September 2001, the combination of $R_{t}, R_{t-1}$, and $R_{t-2}$ would be collinear with a month indicator for September 2001. 
TABLE B1

Response across Other Credit Card Accounts $(N=204,747)$

\begin{tabular}{lccccc}
\hline \hline & \multicolumn{2}{c}{ Other Balances } & & \multicolumn{2}{c}{ Balances } \\
\cline { 2 - 3 } \cline { 5 - 6 } & Coefficient & $\begin{array}{c}\text { Standard } \\
\text { Error }\end{array}$ & & Coefficient & $\begin{array}{c}\text { Standard } \\
\text { Error }\end{array}$ \\
\hline$R_{i, t-1}$ & 9.1 & 128.7 & & 13.2 & 30.0 \\
$R_{i, t-2}$ & 141.7 & 163.3 & & 24.7 & 37.6 \\
$R_{i, t-4}$ & 148.3 & 138.3 & & 12.3 & 31.3 \\
$R_{i, t-5}$ & 120.1 & 173.6 & & 39.2 & 39.4 \\
$R_{i, t-7}$ & 167.0 & 152.0 & & 41.5 & 32.8 \\
$R_{i, t-8}$ & 150.2 & 192.8 & & 50.0 & 41.0 \\
Test: $\left\{R_{i, t-s}\right\}$ joint & & & & .81 \\
\multicolumn{1}{c}{ significance } & & .57 & & \\
\hline
\end{tabular}

NoтE.-Other balances are month-end balances on all other, nonsample credit cards held by the sample account holders, using the quarterly credit bureau data. These data are available in June, September, and December 2001 and March 2002. (The specification includes the corresponding month indicator variables.) For each month of data, the coefficients on $R_{t-s}$ show whether other balances are larger or smaller for account holders who received their rebates earlier (in July and August 2001), relative to those who received their rebates later (in September 2001). See the text ear ( $\left\{R_{t-s} \mid s=1,2,4,5,7,8\right\}$. Balances represent month-end balances on the accounts in the main sample. For comparability this variable is used only in the same months for which other balances are available from the credit bureaus. The standard errors are adjusted for heteroscedasticity across accounts as well as serial correlation within accounts.

their rebates in August (July) 2001, relative to the balances in September 2001 of those who received their rebates in September 2001. The resulting point estimates for $R_{t-1}$ and $R_{t-2}$ are positive. This suggests that other balances increased between the month of receipt and the next two months, though the estimates are not statistically significant. Similarly, the point estimates for $R_{t-4}$ and $R_{t-5}$, and for $R_{t-7}$ and $R_{t-8}$, are also positive, suggesting that the balances of the earlier recipients remain higher through December 2001 and March 2002. However, these estimates are again insignificant, and jointly all the differences together $\left\{R_{t-s} \mid s=1,2,4,5,7,8\right\}$ are also insignificant. Hence these conclusions must be qualified. ${ }^{36}$ For comparison, table B1 applies the same specification to the balances of the accounts in the main sample, using the data only for the same four months for which other balances are available from the credit bureaus. The results are qualitatively similar, with all the regressors $R_{t-s}$ being positive though insignificant. Hence, with the noted qualification, the response of other credit cards appears if anything to reinforce (or at least not to offset) the responses estimated above for the accounts in the main sample.

\section{Appendix C}

\section{The Data}

The main unit of analysis in the data is an individual credit card account. The central account billing statement data (i.e., total payments and spending, and debt) are available by cycle-month. Debt includes only interest-incurring bal-

${ }^{36}$ Eventually the balances of all three groups of rebate recipients should converge. However, as noted, the estimated differences between the groups are not significant even in the short run. Also, these results do not pin down the overall level of balances and so cannot rule out a decline in balances in the month of receipt $(s=0)$. Note, however, that balances include both debt and transactions balances, so their behavior can differ from that of debt. 
ances (i.e., balances rolled over into the next month), not transactions balances (i.e., balances paid off).

The credit bureaus store their information by individual borrower. The credit bureau data on other balances record total month-end balances across all other credit cards held by the same account holder. This includes transactions balances: The credit bureaus do not separately record spending and debt. (For additional discussion of credit bureau data, see, e.g., Musto and Souleles [2006].) The issuer obtained the credit bureau data every three months. For consistency, the usage ratio is defined as month-end balances on the account in the sample divided by (other balances $+\$ 1$ ), using the most recent credit bureau data on other balances. If both the numerator and other balances in the denominator of this ratio are zero or if balances are negative, the ratio is set to missing. In table 3 , if a variable used to split the sample is missing, the corresponding observation is dropped from the corresponding regression.

The data set contains a representative sample of accounts open as of June 2000, with the following exclusions: $(a)$ accounts that are bankrupt or two or more months delinquent, or otherwise frozen; and $(b)$ accounts that are dormant/closed, including, for example, credit cards that were issued but never activated. Consistently with the data provider's standard practice given the available data fields, dormant/closed accounts were identified as those without any retail activity in the previous three quarters.

\section{References}

Auerbach, Alan J. 2002. "The Bush Tax Cut and National Saving." Nat. Tax I. 55 (September): 387-407.

Blinder, Alan S. 1981. "Temporary Income Taxes and Consumer Spending." I.P.E. 89 (February): 26-53.

Blinder, Alan S., and Angus Deaton. 1985. "The Time Series Consumption Function Revisited." Brookings Papers Econ. Activity, no. 2: 465-511.

Bodkin, Ronald G. 1959. "Windfall Income and Consumption." A.E.R. 49 (September): $602-14$.

Browning, Martin, and M. Dolores Collado. 2001. "The Response of Expenditures to Anticipated Income Changes: Panel Data Estimates.” A.E.R. 91 (June): 681-92.

Browning, Martin, and Annamaria Lusardi. 1996. "Household Saving: Micro Theories and Micro Facts." J. Econ. Literature 34 (December): 1797-1855.

Carroll, Christopher D. 1992. "The Buffer-Stock Theory of Saving: Some Macroeconomic Evidence." Brookings Papers Econ. Activity, no. 2: 61-135.

Chimerine, Lawrence. 1997. "Americans in Debt: The Reality." MasterCard International.

Federal Reserve Board of Governors. 2007. "G.19: Consumer Credit." http:// www.federalreserve.gov/releases/g19/.

Gross, David B., and Nicholas S. Souleles. 2002. "Do Liquidity Constraints and Interest Rates Matter for Consumer Behavior? Evidence from Credit Card Data." O.J.E. 117 (February): 149-85.

Hsieh, Chang-Tai. 2003. "Do Consumers React to Anticipated Income Changes? Evidence from the Alaska Permanent Fund." A.E.R. 93 (March): 397-405.

Jappelli, Tullio. 1990. "Who Is Credit Constrained in the U.S. Economy?" O.I.E. 105 (February): 219-34.

Jappelli, Tullio, Jörn-Steffen Pischke, and Nicholas S. Souleles. 1998. "Testing 
for Liquidity Constraints in Euler Equations with Complementary Data Sources." Rev. Econ. and Statis. 80 (May): 251-62.

Johnson, David S., Jonathan A. Parker, and Nicholas S. Souleles. 2006. "Household Expenditure and the Income Tax Rebates of 2001." A.E.R. 96 (December): 1589-1610.

Kiefer, Donald, et al. 2002. "The Economic Growth and Tax Relief Reconciliation Act of 2001: Overview and Assessment of Effects on Taxpayers." Nat. Tax I. 55 (March): 89-117.

Kreinin, Mordechai E. 1961. "Windfall Income and Consumption: Additional Evidence." A.E.R. 51 (June): 388-90.

McNees, Stephen K. 1973. "Tax Refunds and Consumer Spending." New England Econ. Rev. (January/February): 3-11.

Modigliani, Franco, and Charles Steindel. 1977. "Is a Tax Rebate an Effective Tool for Stabilization Policy?" Brookings Papers Econ. Activity, no. 1: 175-203.

Musto, David K., and Nicholas S. Souleles. 2006. "A Portfolio View of Consumer Credit.” I. Monetary Econ. 53 (January): 59-84.

Parker, Jonathan A. 1999. "The Reaction of Household Consumption to Predictable Changes in Social Security Taxes.” A.E.R. 89 (September): 959-73.

Poterba, James M. 1988. "Are Consumers Forward Looking? Evidence from Fiscal Experiments." A.E.R. Papers and Proc. 78 (May): 413-18.

Reis, Ricardo. 2006. "Inattentive Consumers.” L. Monetary Econ. 53 (November): 1761-1800.

Shapiro, Matthew D., and Joel B. Slemrod. 1995. "Consumer Response to the Timing of Income: Evidence from a Change in Tax Withholding." A.E.R. 85 (March): 274-83. 96. . 2003a. "Consumer Response to Tax Rebates." A.E.R. 93 (March): 381-

2003b. "Did the 2001 Tax Rebate Stimulate Spending? Evidence from Taxpayer Surveys." In Tax Policy and the Economy, vol. 17, edited by James M. Poterba. Cambridge, MA: MIT Press (for NBER).

Shea, John. 1995. "Union Contracts and the Life-Cycle/Permanent-Income Hypothesis." A.E.R. 85 (March): 186-200.

Slemrod, Joel B., Charles Christian, Rebecca London, and Jonathan A. Parker. 1997. "April 15 Syndrome." Econ. Inquiry 35 (October): 695-709.

Souleles, Nicholas S. 1999. "The Response of Household Consumption to Income Tax Refunds.” A.E.R. 89 (September): 947-58.

- 2000. "College Tuition and Household Savings and Consumption." I. Public Econ. 77 (August): 185-207.

. 2002. "Consumer Response to the Reagan Tax Cuts." I. Public Econ. 85 (July): 99-120.

. 2004. "Expectations, Heterogeneous Forecast Errors, and Consumption: Micro Evidence from the Michigan Consumer Sentiment Surveys." I. Monev. Credit, and Banking 36 (February): 39-72.

Stephens, Melvin, Jr. 2003. “3rd of tha Month': Do Social Security Recipients Smooth Consumption between Checks?” A.E.R. 93 (March): 406-22.

. 2005. "The Consumption Response to Predictable Changes in Discretionary Income: Evidence from the Repayment of Vehicle Loans." Manuscript, Heinz School, Carnegie-Mellon Univ.

- 2006. "Paycheque Receipt and the Timing of Consumption." Econ. I. 116 (July): 680-701.

Wilcox, David W. 1989. "Social Security Benefits, Consumption Expenditure, and the Life Cycle Hypothesis.” L.P.E. 97 (April): 288-304. 
1990. "Income Tax Refunds and the Timing of Consumption Expenditure." Manuscript, Fed. Reserve Bd. Governors, Washington, DC.

Yoo, Peter S. 1998. "Still Charging: The Growth of Credit Card Debt between 1992 and 1995." Fed. Reserve Bank St. Louis Rev. 80 (January/February): 1927. 